\title{
Functional Specialization of Male and Female Vocal Motoneurons
}

\author{
Ayako Yamaguchi, ${ }^{1,2}$ Leonard K. Kaczmarek, ${ }^{2}$ and Darcy B. Kelley ${ }^{1}$ \\ ${ }^{1}$ Department of Biological Sciences, Columbia University, New York, New York 10027, and 2Department of Pharmacology, Yale University School of \\ Medicine, New Haven, Connecticut 06520
}

\begin{abstract}
Vocal behaviors of African clawed frogs (Xenopus laevis) are produced by a single pair of muscles. This simplification, relative to other vertebrates, allows us to more easily determine how CNS motor pathways function to produce sex-specific songs. We describe here certain sexually differentiated properties of vocal motoneurons that are matched to male and female vocal demands. Both active and passive membrane properties differ between the sexes. Male motoneurons have lower input resistances and larger membrane capacitances than female motoneurons. Two distinct firing patterns are found, in different proportions, in males and females. The strongly adapting neurons that predominate in males initiate spikes at short, reliable latencies, whereas the weakly adapting motoneurons characteristic of females translate graded levels of depolarization into different firing rates. Low-threshold potassium currents $\left(I_{\mathrm{KL}}\right)$ predominate in males. Hyperpolarization-activated cationic currents $\left(I_{\mathrm{H}}\right)$ are found almost exclusively in males. Modeling results indicate that sextypical active and passive properties can account for the occurrence of strongly and weakly adapting spike trains in the sexes. In particular, $I_{\mathrm{KL}}$ seem to play an important role in determining the firing patterns of neurons. We suggest that these physiological differences facilitate transformation of synaptic inputs into male- and female-specific outputs that generate sexually distinct songs in vivo.
\end{abstract}

Key words: sex differences; vocal communication; firing properties; motoneurons; ion currents; intrinsic membrane properties; Xenopus laevis

\section{Introduction}

Courtship vocalizations have provided insights into the neural basis of sexually distinct behaviors. Most attention has been directed to songbirds in which activity in telencephalic neurons can be correlated with the acoustic characteristics of songs ( $\mathrm{Yu}$ and Margoliash, 1996; Vu et al., 1998; Hahnloser et al., 2002). The motor programs that actually produce the sound elements in these songs are poorly understood, primarily because their study is complicated by the requirement for concomitant respiration and by the involvement of multiple vocal muscles (Suthers et al., 1999). African clawed frogs (Xenopus laevis) provide a simpler system in which to address the question of how male and female vocalizations are produced.

Xenopus laevis communicate during the breeding season using underwater calls that consist of click trains. Males express six distinct song types distinguished by click rates $(2-80 \mathrm{~Hz})$; each has a unique and stereotyped temporal pattern (Kelley, 2002). The most common male vocalization is the advertisement call produced for hours at a time during the breeding season (Tobias et al., 2003). This song consists of a highly stereotyped alternation of 33 and $77 \mathrm{~Hz}$ click phrases (Kelley, 2002). Female calls are slower $(2-20 \mathrm{~Hz})$, and click rates are more variable than those of

\footnotetext{
Received July 22, 2003; revised 0ct. 23, 2003; accepted 0ct. 24, 2003.

This work was supported by National Institutes of Health (NIH)-National Research Service Award NS10881, the Grass Foundation (A.Y.), and by NIH Grants NS18492 (L.K.K.) and NS23684 (D.B.K.).

Correspondence should be addressed to Ayako Yamaguchi, Department of Biology, 5 Cummington Street, Boston University, Boston, MA 02215. E-mail: ay@bu.edu.

Copyright $\odot 2003$ Society for Neuroscience $\quad$ 0270-6474/03/2311568-09\$15.00/0
}

males (Tobias et al., 1998). The most common female call is the release call produced when a sexually unreceptive female is clasped by a male. Clicks of both sexes are produced by the contraction of paired laryngeal muscles and subsequent movements of arytenoid disks (Tobias and Kelley, 1987; Yager, 1992). Recordings from the laryngeal nerve of calling frogs have demonstrated that male-typical rapid click trains are produced by rapid and highly synchronous firing, whereas female-typical slower click trains are subserved by slow and less synchronous firing of vocal (laryngeal) motoneurons (Yamaguchi and Kelley, 2000).

How are these sexually distinct firing patterns generated? Temporal patterns of rhythmic behavior such as breathing in mammals and chewing in crabs are produced by central pattern generating (CPG) networks (for review, see Marder and Bucher, 2001). Groups of hindbrain neurons that participate in rhythmic vocal activity have been identified in the leopard frog (Schmidt, 1976); homologs in Xenopus project directly to the laryngeal motor nucleus (Wetzel et al., 1985). CPG networks of Xenopus may generate sex-specific vocal rhythms, and vocal motoneurons simply pass these rhythms on to laryngeal muscles to produce clicks. However, because motoneurons in other systems are known to be equipped with intrinsic membrane properties that actively shape their final outputs (Kiehn et al., 2000), vocal motoneurons could also play a role in generating sex-specific rhythms by converting premotor synaptic input into specific, patterned firing outputs.

In this study, we asked whether the physiological properties of vocal motoneurons themselves are differentiated in male and female Xenopus. To address this question, we have developed a 
brainstem slice preparation that permits direct recording from laryngeal motoneurons. Using this preparation, we demonstrate that passive and active properties of vocal motoneurons are sexually distinct. The differences suggest that the type of neurons common in males is suitable for encoding accurate temporal information, whereas the type of neurons characteristic of females is more appropriate for encoding rate.

\section{Materials and Methods}

Animals. Male and female Xenopus ( $>9$ gm body weight) were obtained from Nasco (Fort Atkinson, WI) and Xenopus One (Ann Arbor, MI). Males produce vocalizations when they are sexually receptive, and females produce vocalizations most frequently when they are not sexually receptive. Sexually receptive males and nonreceptive females were used for the experiments to compare the intrinsic properties of laryngeal motoneurons under conditions in which the animals are capable of producing sex-specific vocal behaviors. To bring males into a sexually receptive state, $600 \mathrm{IU}$ of human chorionic gonadotropin (Sigma, St. Louis, MO) was injected at least $8 \mathrm{hr}$ before decapitation, which typically induced males to vocalize before they were used for the experiment. Females were not treated with hormones; nonreceptive females readily produce release calls when clasped by males.

Retrograde labeling of laryngeal motoneurons. Because the fourth rootlet of nerve IX-X contains almost all axons of laryngeal motoneurons (Simpson et al., 1986), this class of neurons could be selectively labeled by retrograde transport with Alexa 594 biocytin (5\%; Molecular Probes, Eugene, OR) before slice preparation. Frogs were anesthetized with MS222 (Sigma) and perfused transcardially with ice-cold, oxygenated saline via the aorta, and the brain was removed from the skull. All the rootlets of nerve IX-X, except for the fourth, were trimmed close to the brain stem to prevent dye diffusion. The distal end of the fourth rootlet was placed in a small well constructed of Vaseline and filled with dye. The brain was maintained at $4^{\circ} \mathrm{C}$ in oxygenated saline for at least $6 \mathrm{hr}$ to allow retrograde labeling of motoneuron somata.

Slice preparation. The brainstem was attached to a vibratome stage (Lancer Series 1000; Technical Products International, St. Louis, MO) and sliced transversely (250-300 $\mu \mathrm{m}$ in thickness) in ice-cold, partially frozen slicing solution. The slices were then transferred slowly back into saline over the following $30 \mathrm{~min}$.

Electrophysiological recordings. Each slice was placed in a recording chamber mounted on a Zeiss Axioskop microscope fitted with infrareddifferential interference contrast (IR-DIC), fluorescent optics and a $63 \times$ water immersion objective. The chamber was perfused continuously $\left(1.25 \mathrm{ml} / \mathrm{min}^{-1}\right)$ with oxygenated saline. Laryngeal motoneurons were identified visually using fluorescence optics first, and whole-cell recordings were then obtained using IR-DIC optics. An Axoclamp amplifier (Axon Instruments, Foster City, CA) in bridge-balance mode was used for current clamp experiments, and an EPC 7 (HEKA, Lambrecht, Germany) was used for both current- and voltage-clamp experiments. The patch electrodes were pulled from thick-walled borosilicate glass with filament (WPI, Sarasota, FL) using a Sutter Flaming/Brown micropipette puller (model P87; Sutter Instruments, Novato, CA). These pipettes had a resistance of 1.5-6 $\mathrm{M} \Omega$ when filled with an intracellular solution. For pharmacological blockade of hyperpolarization-activated cationic currents $\left(I_{\mathrm{H}}\right), 2 \mathrm{~mm} \mathrm{CsCl}$ or $100 \mu \mathrm{M}$ ZD7288 (Tocris Cookson, Ballwin MO) was included in the saline. To determine the reversal potential of $I_{\mathrm{H}}$, neurons were held at -40 and $-110 \mathrm{mV}$ and stepped to $50-100 \mathrm{mV}$ with $10 \mathrm{mV}$ increments. The difference between these two $I-V$ relationships provides a measure of $I_{\mathrm{H}}$, and the reversal potential was estimated by determining where the slope of the difference current crosses the voltage axis.

The series resistance was $<15 \mathrm{M} \Omega$, and the compensation for series resistance was between 70 and $90 \%$ with a lag of $20 \mu \mathrm{sec}$. Errors in membrane potential were calculated based on the uncompensated series resistance and the current amplitude and then corrected for the additional analyses. Stimulus currents and voltage steps were generated using pCLAMP6 software (Axon Instruments) for current- and voltage-clamp experiments, respectively. Data were digitized and acquired at $10 \mathrm{kHz}$ with the same software running on a personal computer. All recordings were performed at room temperature. Analysis of membrane potential and current kinetics was performed on Clampfit (Axon Instruments) and Origin software (Microcal Software, Northampton, MA).

Solutions. Saline (in mM: $96 \mathrm{NaCl}, 20 \mathrm{NaHCO}_{3}, 2 \mathrm{CaCl}_{2}, 2 \mathrm{KCl}, 0.5$ $\mathrm{MgCl}_{2}, 10$ HEPES, and 11 glucose, $\mathrm{pH} 7.8$ ), slicing solution (in mM: 20 $\mathrm{NaHCO}_{3}, 2 \mathrm{CaCl}_{2}, 2 \mathrm{KCl}, 0.5 \mathrm{MgCl}_{2}, 10 \mathrm{HEPES}, 11$ glucose, and 192 sucrose, $\mathrm{pH} 7.8$ ), and intracellular solution (in mM: $115 \mathrm{KCl}, 2 \mathrm{MgCl}_{2}, 2$ EGTA, 10 HEPES, 2 MgATP, and 0.2 NaGTP, pH 7.4) were used.

Data analysis. Input resistance was calculated from the steady-state membrane potential in response to small hyperpolarizing current pulses $(-10$ to $-540 \mathrm{pA})$. Membrane capacitance of cells was determined based on input resistance and time constant (measured by fitting a single exponential curve to the membrane potential change in response to the injection of small hyperpolarizing currents). When capacitance was measured by calculating the area under the transient current in response to a brief voltage pulse delivered through the pipette (Lindau and Neher, 1988), the results were the same (data not shown).

For voltage-clamp recordings, the mean values of normalized chord conductance were plotted as a function of the corrected test pulse potential. These plots were fitted with the Boltzmann function: $G(V \mathrm{~m}) /$ $G \max =1 /\left\{1+\exp \left[\left(V \mathrm{~m}-V_{1 / 2} / k\right)\right]\right\}$, where $G(V \mathrm{~m})$ is the chord conductance at membrane potential $V \mathrm{~m}, G \max$ is maximal chord conductance, $V_{1 / 2}$ is the voltage of half-maximal conductance, and $k$ is a slope factor. Because of the large membrane currents, the membrane potential was depolarized only to $0 \mathrm{mV}$, and the chord conductance did not reach its maximum. Thus, the Boltzmann functions fitted to the data are likely to be shifted to the left. However, because the shift applies to both male and female data, we consider it unlikely to bias the conclusions drawn from these analyses.

Current densities of outward currents were also calculated based on the current amplitude and the membrane capacitance. The time constants of $I_{\mathrm{H}}$ activation were fitted with a single exponential function in Clampfit (Axon Instruments).

Numerical simulations. Numerical simulations were performed using Hodgkin-Huxley-like equations similar to those used previously to model neurons of the inferior colliculus and the medial nucleus of the trapezoid body (Liu and Kaczmarek, 1998; Wang et al., 1998; Richardson and Kaczmarek, 2000). The responses of the cells were simulated by integration of the equation $-\mathrm{C} \mathrm{dV/dt}=I_{\mathrm{Na}}+I_{\mathrm{KL}}+I_{\mathrm{KH}}+I_{\mathrm{H}}+I_{\mathrm{L}}+$ $I_{\text {ext(t) }}$, where $I_{\mathrm{Na}}$ represents sodium current; $I_{\mathrm{KL}}$ and $I_{\mathrm{KH}}$ represent lowand high-threshold components of potassium current, respectively; $I_{\mathrm{H}}$ represents hyperpolarization-activated cationic current; $I_{L}$ is the leakage current, and external currents $I_{\text {ext(t) }}$ were presented as step currents.

$I_{\mathrm{Na}}$ and $I_{\mathrm{L}}$ were given by the equations $I_{\mathrm{Na}}=\mathrm{g}_{\mathrm{Na}} \mathrm{m}^{3} \mathrm{~h}(V-50)$ and $I_{\mathrm{L}}=$ $\mathrm{g}_{\mathrm{L}}\left(V-E_{\mathrm{L}}\right)$, respectively. For male motoneurons, the low- and highthreshold potassium currents and the hyperpolarization-activated cationic current were provided by the equations $I_{\mathrm{KL}}=\mathrm{g}_{K L} \mathrm{j}(V+80), I_{\mathrm{KH}}=$ $\mathrm{g}_{K H} \mathrm{p}^{3}(V+80)$, and $I_{\mathrm{H}}=\mathrm{g}_{H} \mathrm{n}(V+30)$. The evolution of the variables $m, h, j, p$, and $n$ was determined by Hodgkin-Huxley-like equations as described by Perney and Kaczmarek (1997). Parameters were fit to match mean amplitudes and time courses recorded in either male or female motoneurons. For all model neurons, $E_{\mathrm{L}}=-60 \mathrm{mV}$. For model male motoneurons, the capacitance $C$ ranged from 0.16 to $0.18 \mathrm{nF}$, and $\mathrm{g}_{L}$ from 0.00877 to $0.016 \mu \mathrm{S}$ (for the example in Fig. $6 a$ : $C=0.16 \mathrm{nF}, \mathrm{g}_{L}=$ $0.016 \mu \mathrm{S})$. Sodium current parameters (gNa, $k_{\alpha \mathrm{m}}, \eta_{\alpha \mathrm{m}}, k_{\beta \mathrm{m}}, \eta_{\beta \mathrm{m}}, k_{\alpha \mathrm{h}}$, $\eta_{\alpha \mathrm{h}}, k_{\beta \mathrm{h}}$, and $\left.\eta_{\beta \mathrm{h}}\right)$, low-threshold potassium current parameters $\left(\mathrm{g}_{K L}\right.$, $k_{\alpha \mathrm{j}}, \eta_{\alpha \mathrm{j}}, k_{\beta \mathrm{j}}$, and $\left.\eta_{\beta \mathrm{j}}\right)$, high-threshold potassium current parameters $\left(\mathrm{g}_{K H}, k_{\alpha \mathrm{p}}, \eta_{\alpha \mathrm{p}}, k_{\beta \mathrm{p}}\right.$, and $\left.\eta_{\beta \mathrm{p}}\right)$, and hyperpolarization-activated cationic current parameters $\left(\mathrm{g}_{H}, k_{\alpha \mathrm{n}}, \eta_{\alpha \mathrm{n}}, k_{\beta \mathrm{n}}\right.$, and $\eta_{\beta \mathrm{n}}$ ) for male motorneurons are given in Table 1. For female motoneurons, $C$ ranged from 0.062 to $0.084 \mathrm{nF}$, and $\mathrm{g}_{L}$ from 0.0052 to $0.00568 \mu \mathrm{S}$ (for the example in Fig. $6 e$ : $\left.C=0.084 \mathrm{nF}, \mathrm{g}_{L}=0.0052 \mu \mathrm{S}\right)$. Sodium current parameters for females were identical to those for males, except for maximal conductance (Table 1) (for the example in Fig. 6, gNa $=1.0 \mu \mathrm{S}$ ). The minor component of low-threshold current in female motoneurons was modeled using the equation $I_{\mathrm{KL}}=\mathrm{g}_{K L} \mathrm{jk}(80-V)$, where $k$, like the other gating variables, was determined by Hodgkin-Huxley-like equations and the parameters $k_{\alpha \mathrm{k}}, \eta_{\alpha \mathrm{k}}, k_{\beta \mathrm{k}}$, and $\eta_{\beta \mathrm{k}}$ are given in Table 1 (Perney and Kaczmarek, 1997). 
Table 1. Parameters used to model sodium currents, low-threshold potassium currents, high-threshold potassium currents, and hyperpolarization-activated cationic currents of male and female motoneurons

\begin{tabular}{|c|c|c|c|c|c|c|c|c|c|}
\hline \multicolumn{10}{|c|}{ Sodium currents } \\
\hline Gender & $G_{\mathrm{Na}}(\mu S)$ & $k_{\alpha \mathrm{m}}\left(\mathrm{msec}^{-1}\right)$ & $\eta_{\alpha \mathrm{m}}\left(\mathrm{mV}^{-1}\right)$ & $k_{\beta m}\left(\mathrm{msec}^{-1}\right)$ & $\eta_{\beta \mathrm{m}}\left(\mathrm{mV}^{-1}\right)$ & $k_{\alpha \mathrm{h}}\left(\mathrm{msec}^{-1}\right)$ & $\eta_{\alpha \mathrm{h}}\left(\mathrm{mV}^{-1}\right)$ & $k_{\beta \mathrm{h}}\left(\mathrm{msec}^{-1}\right)$ & $\eta_{\beta \mathrm{h}}\left(\mathrm{mV}^{-1}\right)$ \\
\hline Male & 1.7 & 76.4 & 0.037 & 6.93 & -0.043 & 0.000419 & 0.1233 & 1.249 & 0.0367 \\
\hline Female & $0.75-1.0$ & 76.4 & 0.037 & 6.93 & -0.043 & 0.000419 & 0.1233 & 1.249 & 0.0367 \\
\hline \multicolumn{10}{|c|}{ Low-threshold potassium currents } \\
\hline Gender & $g_{\mathrm{KL}}(\mu \mathrm{S})$ & $k_{\alpha \mathrm{j}}\left(\mathrm{msec}^{-1}\right)$ & $\eta_{\alpha \mathrm{j}}\left(\mathrm{mV}^{-1}\right)$ & $k_{\beta \mathrm{j}}\left(\mathrm{msec}^{-1}\right)$ & $\eta_{\beta \mathrm{j}}\left(\mathrm{mV}^{-1}\right)$ & $k_{\alpha \mathrm{k}}\left(\sec ^{-1}\right)$ & $\eta_{\alpha \mathrm{k}}\left(\mathrm{mV}^{-1}\right)$ & $k_{\beta \mathrm{k}}\left(\sec ^{-1}\right)$ & $\eta_{\beta \mathrm{k}}\left(\mathrm{mV}^{-1}\right)$ \\
\hline Male & 0.1 & 0.167 & 0.0125 & $0.03192-0.03253$ & -0.0275 & & & & \\
\hline Female & $0.03-0.035$ & 0.167 & 0.0125 & $0.06243-0.07438$ & -0.0275 & 0.00816 & -0.06858 & 0.9915 & 0.01142 \\
\hline \multicolumn{10}{|c|}{ High-threshold potassium currents } \\
\hline Gender & \multicolumn{2}{|c|}{$G_{\mathrm{KH}}(\mu S)$} & \multicolumn{2}{|c|}{$k_{\alpha p}\left(\mathrm{msec}^{-1}\right)$} & \multicolumn{2}{|l|}{$\eta_{\alpha p}\left(\mathrm{mV}^{-1}\right)$} & \multicolumn{2}{|l|}{$k_{\beta p}\left(\mathrm{msec}^{-1}\right)$} & $\eta_{\beta p}\left(\mathrm{mV}^{-1}\right)$ \\
\hline Male & \multirow{2}{*}{\multicolumn{2}{|c|}{$\begin{array}{l}0.2 \\
0.085-8.0\end{array}$}} & \multicolumn{2}{|l|}{0.38} & \multicolumn{2}{|l|}{0.022} & \multicolumn{2}{|l|}{0.1753} & -0.043 \\
\hline Female & & & 0.38 & & 0.022 & & 0.1753 & & -0.043 \\
\hline \multicolumn{10}{|c|}{ Hyperpolarization-activated cationic currents } \\
\hline Gender & \multicolumn{2}{|c|}{$G_{H}(\mu S)$} & \multicolumn{2}{|c|}{$k_{\alpha \mathrm{n}}\left(\sec ^{-1}\right)$} & $\eta_{\alpha \mathrm{n}}\left(\mathrm{mV}^{-1}\right)$ & & \multicolumn{2}{|l|}{$k_{\beta \mathrm{n}}\left(\sec ^{-1}\right)$} & $\eta_{\beta \mathrm{n}}\left(\mathrm{mV}^{-1}\right)$ \\
\hline Male & \multicolumn{2}{|c|}{0.04} & \multicolumn{2}{|l|}{0.0038} & -0.05565 & & \multicolumn{2}{|l|}{0.3095} & 0.00565 \\
\hline
\end{tabular}

The equation and kinetic parameters for the high-threshold potassium current were identical to those of male motoneurons, and the $g_{K H}$ could be varied over a very wide range $(0.085-8.0 \mu \mathrm{S})$ with no change in subthreshold behavior or in the general pattern of firing responses to depolarizing current pulses (for the example in Fig. $6 e, \mathrm{~g}_{K H}=8.0 \mu \mathrm{S}$ ). For some combinations of model female parameters, the model gave rise to multiple steady states, which resulted from a "window current" produced by the sodium current and could be eliminated by an increase in $\mathrm{g}_{\mathrm{KH}}$. Hyperpolarization-activated cationic current was absent from female neurons $\left(\mathrm{g}_{H}=0\right)$. Parameters for feminized male motoneurons were identical to those for male motoneurons, with the exceptions of those for the low-threshold potassium current, which were either identical to those of female motoneurons with a conductance $g_{K L}=0.2 \mu \mathrm{S}$, or the parameters for the male low-threshold current were simply modified to activate at more positive potentials comparable with those in females (as shown in Fig. 6, $b$ and $c$, where $\mathrm{g}_{K L}=0.1 \mu \mathrm{S}, k \beta$; changed from $0.03192 \mathrm{msec}^{-1}$ to $0.07438 \mathrm{msec}^{-1}$, with other male parameters unchanged), with or without hyperpolarization-activated cationic current ( $\mathrm{g}_{H}=0.04$ or $0 \mu \mathrm{S}$, respectively). Parameters for the masculinized female motoneurons were identical to those for female motoneurons, with the exceptions of those for the low-threshold potassium current, which were changed to those of the male neurons, activating at more negative potentials (for the example in Fig. 6, $f$ and $g: g_{K L}=0.035 \mu \mathrm{S}, k_{\alpha \mathrm{j}}=0.167$ $\mathrm{msec}^{-1}, \eta_{\alpha \mathrm{j}}=0.0125 \mathrm{mV}^{-1}, k_{\beta \mathrm{j}}=0.03252 \mathrm{msec}^{-1}$, and $\eta_{\beta \mathrm{j}}=-0.0275$ $\mathrm{mV}^{-1}$ ), without or with the addition of the hyperpolarization-activated cationic current $\left(\mathrm{g}_{H}=0\right.$ or $0.025 \mu \mathrm{S}$, respectively).

\section{Results}

\section{Male laryngeal motoneurons require larger depolarizing currents to spike}

Laryngeal motoneurons were identified by retrograde labeling before slice preparation (Fig. 1). Passive membrane properties of motoneurons were characterized using current-clamp recordings in the whole-cell patch configuration. The voltage of spike threshold and the resting membrane potential did not differ between males and females (Table 2). In contrast, the input resistance (measured from the voltage responses to small hyperpolarizing current inputs) was significantly lower in male than in female motoneurons, and the membrane capacitance (calculated from input resistance and membrane time constant) was significantly larger in male than in female motoneurons (Table 2). Consequently, significantly larger depolarizing currents were required to bring male motoneurons to threshold for action potential generation (Table 2). This observation suggests that male motoneurons are larger than female motoneurons.

\section{Firing patterns are sexually distinct}

The firing patterns of male and female motoneurons were characterized using current-clamp recordings. In response to depolarizing current injection, two clearly distinct firing patterns, strongly (Fig. 2a) and weakly (Fig. $2 b$ ) adapting, were observed. Although both firing patterns were seen in male and female neurons, the strongly adapting type was more characteristic of male motoneurons ( $77 \%$ of 39 neurons) and less prevalent in female motoneurons ( $41 \%$ of 27 neurons; Fisher's exact test for sex differences; $p<0.01)$.

In response to just-suprathreshold depolarizing current steps, strongly adapting neurons produced only a single action potential (see voltage responses of a female and a male motoneuron to 0.2 and $0.4 \mathrm{nA}$ of current injection, respectively) (Fig. 2a), whereas weakly adapting neurons typically fired repetitively throughout the stimulus pulse (see voltage response of a female and a male motoneuron to 0.1 and $0.54 \mathrm{nA}$ of current injection, respectively) (Fig. 2b). Additional depolarization caused strongly adapting neurons to fire several action potentials (up to 8 spikes) of diminishing amplitude at the beginning of the stimulation (two spikes of decreasing amplitude evoked in response to larger current injections in male and female neurons are shown in Fig. $2 a$ ). The same treatment caused weakly adapting neurons to generate spikes of constant amplitude; as greater stimulating current was applied, spikes were generated at increasingly faster rates (Fig. 2b).

The spike-onset time (i.e., the latency from the onset of the current pulse to the action potential) differed markedly for strongly and weakly adapting vocal motoneurons (Fig. 2c). For strongly adapting neurons, the first spike almost always occurred within the first $10 \mathrm{msec}$ after depolarization, regardless of stimulus magnitude, whereas the latency to the first spike of a weakly adapting neuron was variable and dependent on the magnitude of depolarization (compare the latency to the first spike in male and female neurons in response to current steps of various amplitude) (Fig. 2a,b). Maximum spike-onset time (the spike latency when a neuron was injected with the minimum amplitude of depolarizing current required to evoke a spike) (Fig. 2a,b, dashed lines) was significantly longer for weakly adapting than 

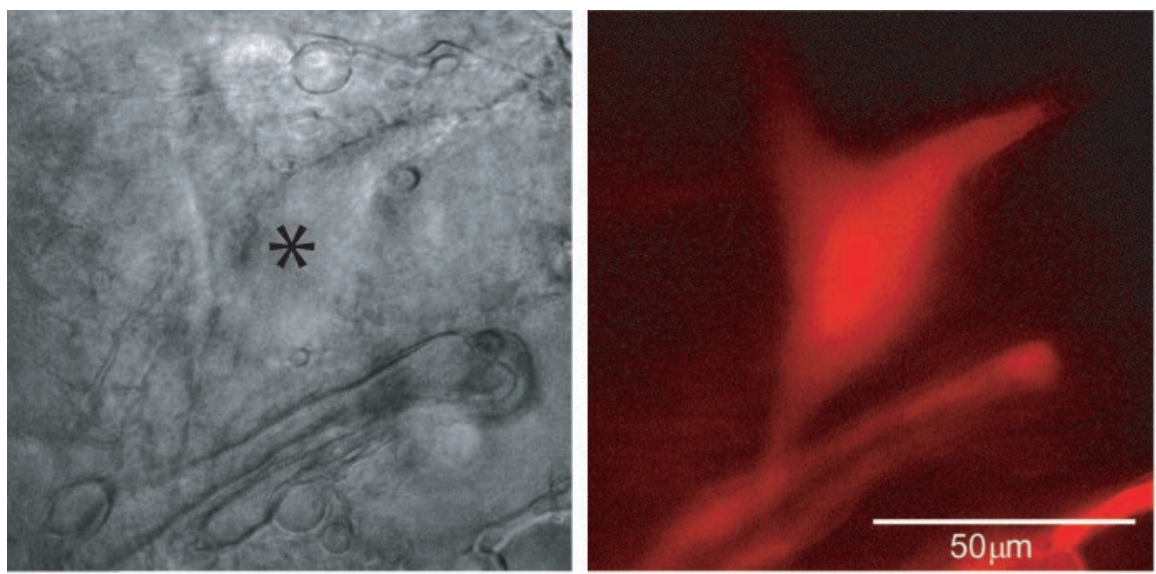

Figure 1. Identification of retrogradely labeled laryngeal motoneurons in a slice preparation. Left, Infra-red differential contrast image. Right, The same field as in the left panel, viewed using fluorescent optics.

for strongly adapting neurons in both sexes (Mann-Whitney $U$ test; $Z=-3.0$ and -3.0 and $p=0.003$ and 0.003 for males and females, respectively) and did not differ between the sexes within each class of neurons (Mann-Whitney $U$ test; $Z=-0.85$ and -1.16 and $p=0.40$ and 0.25 for strongly and weakly adapting neurons, respectively). Thus, Xenopus laryngeal motoneurons can be divided into two distinct populations that differ in how they encode depolarizing current inputs into a discharge pattern, and male and female motor nuclei contain sexually distinct proportions of the two classes of neurons, each class being more typical of one sex.

\section{Voltage-dependent low-threshold potassium currents are sexually distinct}

In response to depolarizing voltage steps, motoneurons produced large outward currents (Fig. $3 a$ ). The outward currents were carried mostly by $\mathrm{K}^{+}$, because substituting $\mathrm{Cs}^{+}$for intracellular $\mathrm{K}^{+}$reduced the current density by $77 \%$.

When the $\mathrm{K}^{+}$currents were measured from a holding potential of $-80 \mathrm{mV}$, the voltage dependence of the currents differed between the sexes. Activation of voltage-dependent currents could be detected at potentials near the resting membrane potential in the majority of male motoneurons (current activation was detected at $-50 \mathrm{mV}$ in $68 \%$ of 47 male neurons), whereas in the majority of female neurons currents were activated only at potentials more positive than $-50 \mathrm{mV}$ (current activation was detected at or above $-40 \mathrm{mV}$ in $67 \%$ of 27 neurons; Fisher's exact test for sex differences; $p<0.01)$. Accordingly, the average voltage of half-maximal conductance $\left(V_{1 / 2}\right)$ was significantly more hyperpolarized, by $-11 \mathrm{mV}$ on average, in male than in female vocal motoneurons $\left(V_{1 / 2}\right.$ mean $\pm \mathrm{SE}=-31.3 \pm 1.3 \mathrm{mV}$ and $-20.1 \pm 1.5 \mathrm{mV}$ for males and females, respectively; MannWhitney $U$ test; $p<0.0001)$, whereas the slope factor $(k)$ was similar $(-6.3 \pm 1.2$ and $-4.9 \pm 2.7$ for males and females, respectively) (Fig. 3b).

When $\mathrm{K}^{+}$currents were measured from a holding potential of $-40 \mathrm{mV}$, however, the voltage dependence of the currents was very similar in the two sexes. The voltage of half-maximal conductance and the slope factor were not significantly different in males and females $\left(V_{1 / 2}\right.$ mean $\pm \mathrm{SE}=-17.5 \pm 1.2$ and $-17.3 \pm$ $1.8 \mathrm{mV}$ for males and females, respectively). In female motoneurons, the voltage of half-maximal conductance of the currents evoked from a holding potential of $-40 \mathrm{mV}$ was very similar to the currents evoked from a holding potential of $-80 \mathrm{mV}$ (Mann-
Whitney $U$ test; $U=243.0 ; p=0.28$ ) (Fig. $3 a, b)$. In contrast, in male motoneurons, the voltage of half-maximal conductance of the currents evoked from the two holding potentials was very different (MannWhitney $U$ test; $U=341.0 ; p<0.0001)$ (Fig. 3a,b). Thus, $\mathrm{K}^{+}$currents seem to comprise two components: a low-threshold current that activates close to the resting potential $(-50 \mathrm{mV})$, present in the majority of male but only in a minority of female laryngeal motoneurons, and a highthreshold current that activates at more depolarized potentials (approximately $-30 \mathrm{mV}$ ) and is similar in male and female motoneurons.

Because potassium currents are known to shape the firing patterns of neurons, we further examined the relationship of firing patterns to total potassium currents in a subset of laryngeal motoneurons from which both current-clamp and voltage-clamp recordings were obtained ( $n=15$ and $\mathrm{N}=6$ for strongly adapting male neurons; $n=8$ and $\mathrm{N}=4$ for strongly adapting female neurons; $n=4$ and $\mathrm{N}=3$ for weakly adapting male neurons; and $n=10$ and $\mathrm{N}=3$ for weakly adapting female neurons; $n$ and $\mathrm{N}$ indicate the number of neurons and the number of animals, respectively). When categorized, by firing type, the voltage dependence of total potassium currents did not differ in males and females (Mann-Whitney $U$ test; strongly adapting neurons: $U=$ 44,59 , and $58, p=0.3,0.9$, and 0.9 ; weakly adapting neurons: $U=8,19$, and $13, p=0.09,0.9$, and 0.3 for $V_{1 / 2}, k$, and voltage of activation, respectively). Therefore, the data for males and females were combined for each firing type for additional analyses.

The presence of low-threshold potassium currents near the resting membrane potential is associated with the strongly adapting firing patterns of male and female laryngeal motoneurons. The average normalized conductances were significantly larger in strongly adapting neurons than in weakly adapting neurons at $-50,-40$, and $-30 \mathrm{mV}$ (Fig. 4) (Mann-Whitney $U$ test; $U=$ 68.0, 68.0, and 75.0, $p=0.004,0.004$, and 0.007 for $-50,-40$, and $-30 \mathrm{mV}$ respectively; the family confidence interval for the six comparisons was set at $95 \%$ with Bonferroni adjustment for $p$ value). Furthermore, when current density near resting membrane potential $(-50 \mathrm{mV})$ was examined, strongly adapting neurons had larger current densities (mean $\pm \mathrm{SE}=1.58 \pm 0.34$ $\mathrm{pA} / \mathrm{pF} ; n=23)$ than weakly adapting neurons $(0.41+0.32 \mathrm{pA} /$ pF; $n=14$; Mann-Whitney $U$ test; $U=100 ; p=0.05)$. Thus, strongly adapting neurons seem to have larger conductance of potassium currents near the resting membrane potential.

\section{Hyperpolarization-activated cationic current is seen only in male motoneurons}

Another type of voltage-dependent ionic current distinguished male from female laryngeal motoneurons. Slow inward currents activated by stepping to negative potentials were detected in nearly all of the male motoneurons examined ( $95.4 \%$ of 87 neurons) but in very few female motoneurons (6.9\% of 31 neurons) (Fig. $5 a$; Fisher's exact test for sex differences; $p<0.001$ ). This inward current was noticeable below $-80 \mathrm{mV}$ (Fig. $5 b$ ); the activation time constant ranged from 200 to $800 \mathrm{msec}$ and was voltage dependent (Fig. 5c). This current is likely to be a hyperpolarization-activated cation current $\left(I_{\mathrm{H}}\right)$, because it is blocked by ZD7288 (highly selective for $I_{\mathrm{H}}$ ) (Harris et al., 1994) 
Table 2. Passive membrane properties of male and female laryngeal motoneurons

\begin{tabular}{|c|c|c|c|c|}
\hline & Male $(\mathrm{N}=15, n=38)$ & Female $(\mathrm{N}=10, n=26)$ & Test statistic & $p$ \\
\hline Spike threshold (mV) & $-31.2 \pm 1.3$ & $-31.9 \pm 1.7$ & $t=-0.3$ & 0.75 \\
\hline Resting membrane potential (mV) & $-49.3 \pm 0.9$ & $-50.4 \pm 1.1$ & $t=0.8$ & 0.43 \\
\hline Input resistance (M\&OHgr;) & $86.9 \pm 10.3$ & $169.9 \pm 21.1$ & $t=3.9$ & $<0.001^{*}$ \\
\hline Membrane capacitance (pF) & $180.8 \pm 11.0^{a}$ & $62.3 \pm 10.6^{b}$ & $t=-4.9$ & $<0.001^{*}$ \\
\hline Minimum currents to evoke an action potential $(\mathrm{pA})$ & $478.6 \pm 45.9$ & $198.7 \pm 48.6$ & $t=-4.0$ & $<0.001^{*}$ \\
\hline
\end{tabular}

$\mathrm{N}$, Number of animals; $n$, number of cells. Values given are mean $\pm \mathrm{SE}$. The first four parameters were measured using current-clamp recordings, and the last parameter was measured using voltage-clamp recordings.

${ }^{a} \mathrm{~N}=11, n=78$.

${ }^{b} \mathrm{~N}=3, n=17$.

\section{a Strongly-adapting type}
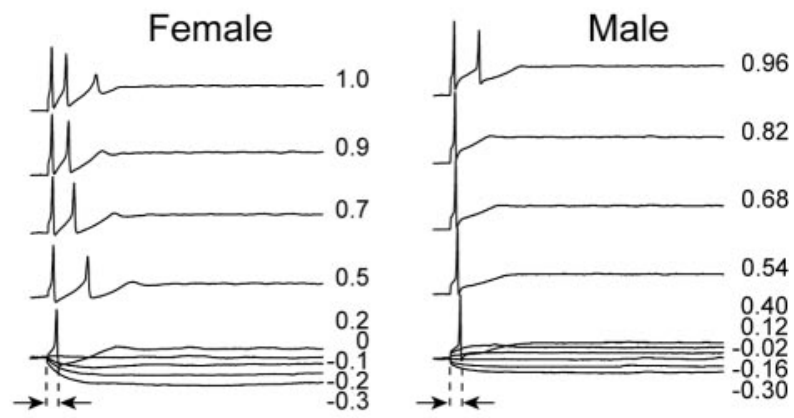

\section{b Weakly-adapting type}

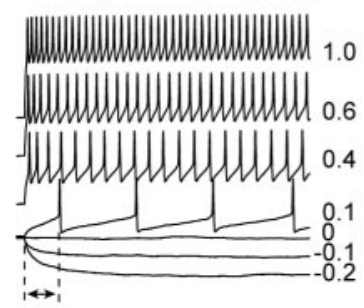

C

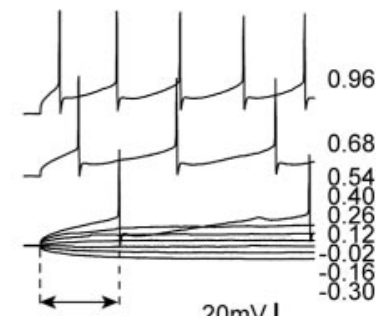

$20 \mathrm{mVL}$

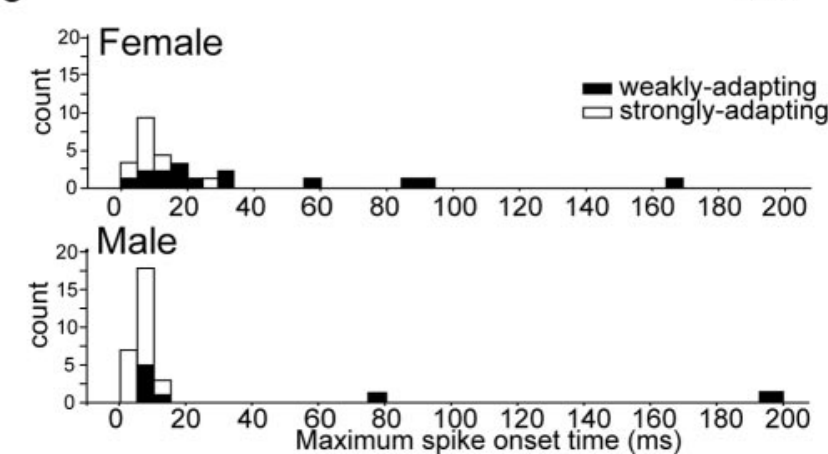

Figure 2. Firing properties of male and female laryngeal motoneurons. $a$, Current-clamp recordings of strongly adapting male and female motoneurons. $b$, Current-clamp recordings of weakly adapting male and female motoneurons. To the right of each trace, the amplitude of injected current in nanoamperes is indicated. Maximum spike onset time of each neuron is indicated by dashed lines. c, Histogram of maximum spike onset time (see Results and Fig. 2, a and $b$ ) of male and female neurons.

(Fig. $5 d$ ) as well as by extracellular $\mathrm{Cs}^{+}$(Fig. 5e) and because the extrapolated reversal potential of the currents $(-28 \mathrm{mV})$ fits within the range for the reversal potential of $I_{\mathrm{H}}$ reported in other species (Pape, 1996). The application of ZD7288 or Cs ${ }^{+}$reduced the amplitude of the instantaneous current amplitude at the beginning of the voltage step in four of eight male motoneurons (Fig. $5 d, e$ ). This observation indicates that, in some neurons, $I_{\mathrm{H}}$ is active at the holding potentials of $-40 \mathrm{mV}$. a.
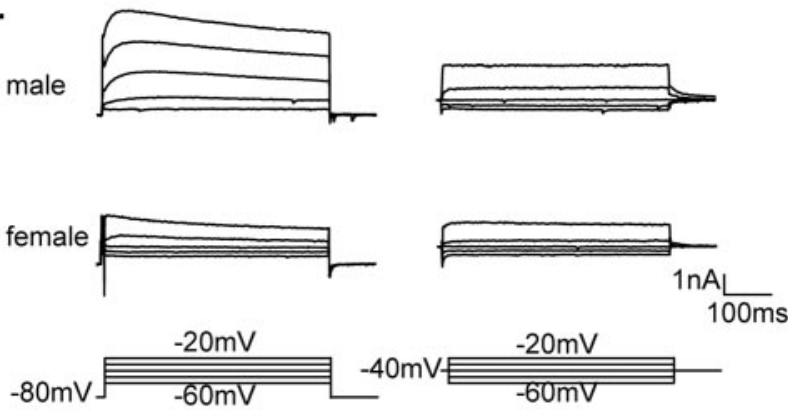

b.

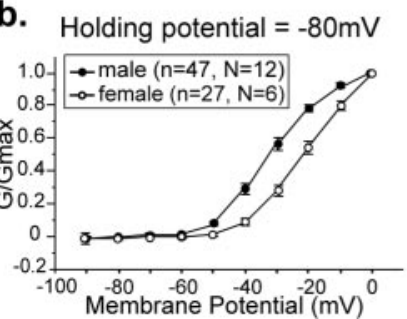

C. Holding potential $=-40 \mathrm{mV}$

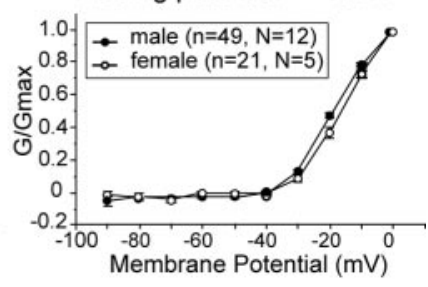

Figure 3. $a$, Voltage-clamp traces of $\mathrm{K}^{+}$current in male and female motoneurons activated from two holding potentials $\left(V_{H}\right):-80$ and $-40 \mathrm{mV}$. Brief inward currents were evoked in some neurons but not all, presumably because the spike initiation site was severed from soma on a slice. $b$, Voltage dependence of currents activated from holding potential of $-80 \mathrm{mV}$ (mean $\pm \mathrm{SE}$ ). The currents were measured at steady state. c, Voltage dependence of highthreshold current activated from a holding potential of $-40 \mathrm{mV}$ (mean $\pm \mathrm{SE}$ ).

The active ionic conductances, together with passive membrane properties, account for firing patterns

To examine the relationship between active ionic conductances, passive membrane properties, and the firing patterns of neurons, we performed numerical simulations of strongly adapting model male and weakly adapting model female motoneurons. The model included voltage-gated sodium currents, low- and highthreshold potassium currents, $I_{\mathrm{H}}$, and leak currents. Model parameters for the low-threshold potassium current were selected to match the mean conductance levels, kinetics, and passive parameters measured directly from strongly adapting male and weakly adapting female motoneurons (see Materials and Methods).

When a model male neuron was stimulated with a series of current steps, it spiked only once in response to suprathreshold stimuli (Fig. 6a). In contrast, when a model female neuron was stimulated with a series of current steps, it fired repetitively (Fig. $6 e$ ). The maximum spike latency was shorter in the model male neuron than in the model female neuron (Table 3).

The weakly and strongly adapting firing patterns may be explained by the potassium currents in the model neuron. To explore this possibility, we plotted the changes in membrane potential, together with the accompanying low-threshold potassium 


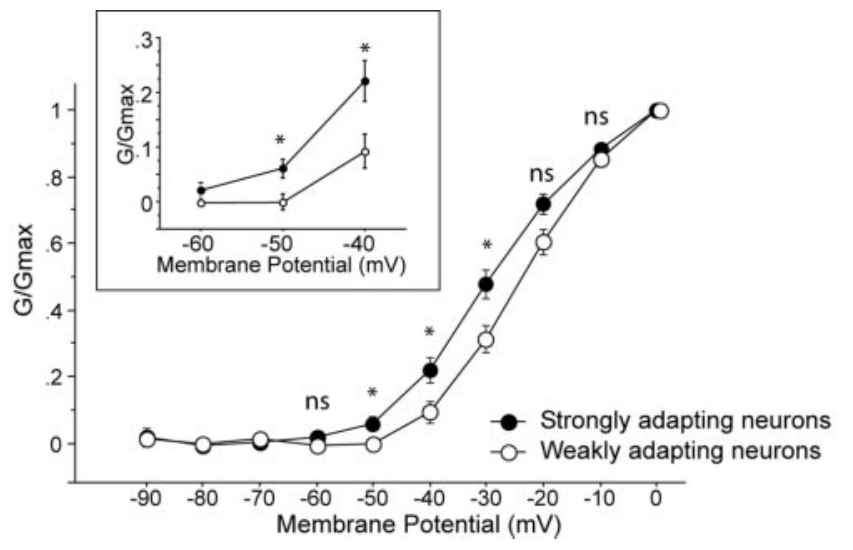

Figure 4. Low-threshold potassium currents and firing patterns of laryngeal motoneurons. Voltage dependence of currents activated from a holding potential of $-80 \mathrm{mV}$ in strongly (O) and weakly adapting $(\bigcirc)$ neurons (mean $\pm \mathrm{SE}$ ). Inset, The voltage dependence of currents between -60 and $-40 \mathrm{mV}$. Asterisks indicate a significant difference of normalized conductances between strongly and weakly adapting neurons. ns, Statistical nonsignificance.

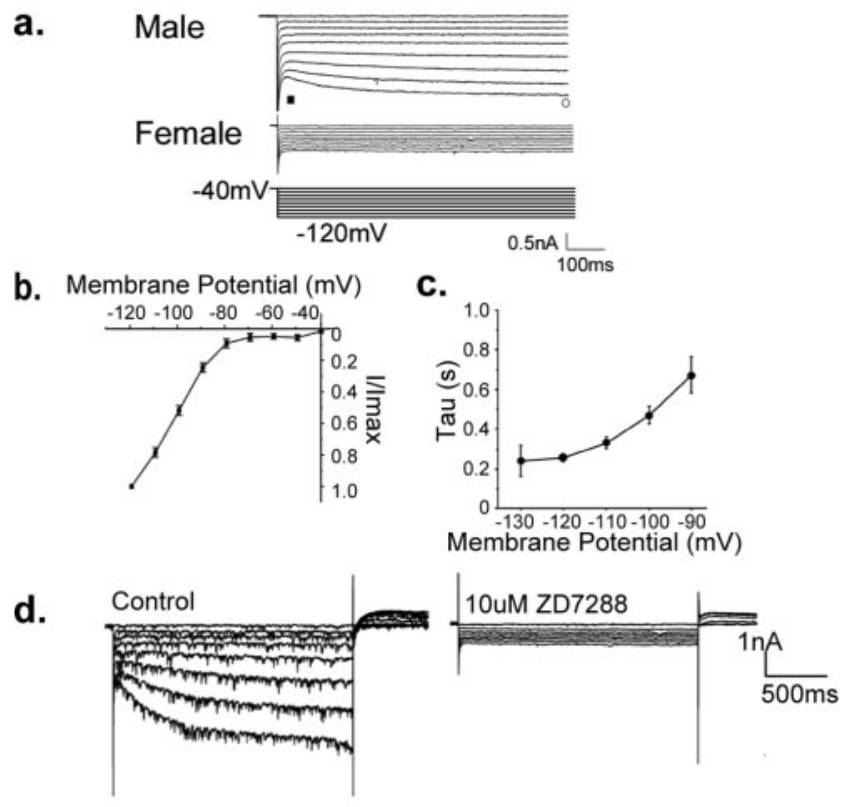

e.
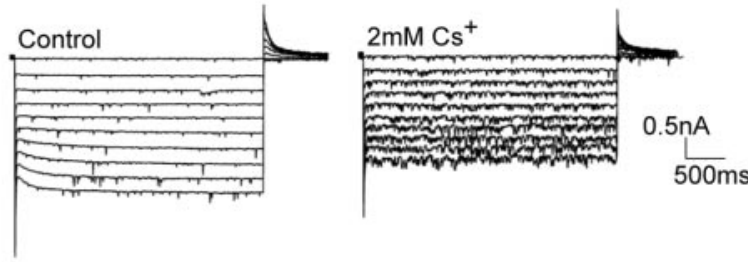

Figure 5. $I_{\mathrm{H}}$ of male laryngeal motoneurons. $a$, Inward currents are activated in most male motoneurons, but not in most female motoneurons, by stepping from -40 to $-120 \mathrm{mV} . b$, Mean normalized currents plotted against test voltages (mean $\pm \mathrm{SE} ; n=25, \mathrm{~N}=10$ ). The currents were measured by subtracting the current at the beginning of the step ( $\square$ ) from the current at the steady state $(O)$ in a.c, Voltage dependence of mean activation time constants of $I_{H}($ mean $\pm S E ; n=12, N=6)$. $d$, The inward current is blocked by ZD7288, a selective blocker of $I_{\mathrm{H}}$, as well as by $\mathrm{Cs}^{+}(e)$.

current, in response to a depolarizing current step in the model male and female neurons (Fig. $6 d, h$ ). The results revealed that rapid sustained activation of the low-threshold potassium conductance in the male model neuron is likely to prevent repetitive spiking after the first action potential (Fig. $6 d$ ).
To further examine the role of low-threshold potassium currents in regulating firing patterns, we substituted the lowthreshold potassium currents of the model male neuron for those of the model female neuron. When the voltage of half-maximal conductance of this current in a model male neuron was altered to the level recorded in females, the neuron fired repeatedly in response to depolarizing currents (Fig. 6b), and the maximum spike latency was increased (Table 3 ). Alternatively, when parameters for the low-threshold component of current in the model female neurons were changed to those of the strongly adapting male neuron that activates at more negative potentials, the neuron fired a single action potential in response to justsuprathreshold current (Fig. $6 f$ ), and the maximum spike latency was decreased (Table 3). Thus, the firing patterns of the male and female model neurons can be converted to weakly and strongly adapting type by substituting the low-threshold potassium currents from the opposite sex.

Because, in strongly adapting male neurons, some activation of the low-threshold potassium current also occurs at the resting potential, removal of this current, or its activation at more positive potentials, also results in depolarization of the membrane resting potential. When the nonselective cation current $I_{\mathrm{H}}$ is further removed from the model male motoneuron, there is a restorative hyperpolarization of the resting membrane potential. The removal of $I_{\mathrm{H}}$ did not alter the pattern of repetitive firing in response to injected currents (Fig. $6 c$ ), but the maximum spike latency was increased (Table 3 ). In contrast, in the model female neuron, the substitution of $I_{\mathrm{KL}}$ resulted in hyperpolarization of the resting potential. The addition of the male $I_{\mathrm{H}}$ component of current to the model female neuron restored the membrane potential. The addition of $I_{\mathrm{H}}$ did not alter the overall firing pattern (Fig. $6 g$ ), although the maximum spike latency was reduced (Table 3 ).

Taken together, the results suggest that the firing patterns of the simulated cells match the strongly and weakly adapting firing patterns; $I_{\mathrm{KL}}$ seems to play an important role in controlling the firing patterns of these neurons, whereas $I_{\mathrm{H}}$ seems to play a role in maintaining the resting membrane potential by counteracting the hyperpolarizing effect of $I_{\mathrm{KL}}$. The spike latency seems to be sensitive to the presence of $I_{\mathrm{KL}}$ and $I_{\mathrm{H}}$.

\section{Discussion}

Male- and female-specific songs of Xenopus are generated by central vocal pathways and conveyed to vocal muscles via laryngeal motoneurons as spike trains, the rate and patterns of which match precisely the vocalizations that are actually produced (Yamaguchi and Kelley, 2000). Here, we show that intrinsic membrane characteristics of male and female vocal motoneurons are also sexually differentiated; passive properties are sexually distinct, and two types of active ionic conductances are more common in male neurons than in female neurons. These properties are likely to account for the strongly and weakly adapting firing patterns characteristic of male and female motoneurons, respectively. We suggest that these physiological differences represent adaptations that allow laryngeal motoneurons to transform synaptic inputs into male- and female-specific outputs that generate sexually-specific songs in vivo.

We found active conductances that are more common in male than in female laryngeal motoneurons. In particular, lowthreshold potassium currents that activate near the resting membrane potential (approximately $-50 \mathrm{mV}$ ) seem to play an important role in determining firing patterns, because their presence correlates well with strongly adapting firing patterns. The voltage 
of half-maximal conductance, $V_{1 / 2}$, is more negative in males, on average by $-11 \mathrm{mV}$, than in females. In the model male neuron, depolarization of their half-maximal conductances resulted in repetitive firing that resembles weakly adapting firing patterns. In the female model neuron, setting the value of the half-maximal conductance to the male value resulted in strongly adapting firing patterns. Thus, it is likely that the expression of low-threshold potassium currents in vocal motoneurons contributes to strongly adapting firing patterns. These currents do not, however, entirely dictate the firing patterns of neurons in which they are expressed. A small proportion of male motoneurons that express low-threshold potassium currents show weakly adapting firing patterns; some female motoneurons that lack the lowthreshold potassium currents show strongly adapting firing patterns. The firing patterns of a neuron are determined by a balance of active and passive membrane properties (Goldman et al., 2001); whereas the low-threshold potassium current plays a role, other factors must also contribute.

$I_{\mathrm{H}}$ is almost exclusively found in male motoneurons. Although $I_{\mathrm{H}}$ typically activates at negative potentials, we were able to detect ZD7288 and Cs-sensitive $I_{\mathrm{H}}$ conductances near the resting membrane potential in some neurons. In these neurons, $I_{\mathrm{H}}$ seems to play a role in controlling the resting membrane potential (Pape, 1996). Moreover, in our computer simulations, the depolarizing drive of $I_{\mathrm{H}}$ was found to counteract the hyperpolarizing influence of the male low-threshold potassium current near rest. A close linkage of the amplitude of $I_{\mathrm{H}}$ to potassium currents has been found in certain lobster neurons, in which overexpression of Shal potassium channels results in a compensatory increase in $I_{\mathrm{H}}$, so as to maintain mean membrane potential and firing pattern (MacLean et al., 2003). Other functional roles of $I_{\mathrm{H}}$ expressed in various neurons in the CNS include regulation of synaptic integration (Magee, 1999) and generation of

pacemakerlike depolarizations (Lüthi and McCormick, 1998). The voltage of $I_{\mathrm{H}}$ activation is known to be modulated by intracellular cAMP such that an increase in cAMP results in activation of $I_{\mathrm{H}}$ at more positive membrane potentials (DiFrancesco and Tortora, 1991; Lutwig et al., 1998, 1999). Thus, under physiological conditions in which cAMP levels become elevated, $I_{\mathrm{H}}$ in male motoneurons may operate near resting membrane potentials (as seen in some male neurons in this study) and could make substantial contributions to synaptic integration.

What types of ion channels underlie male-typical ion currents? The most likely candidates for $I_{\mathrm{H}}$ are hyperpolarizationactivated and cyclic nucleotide-gated (HCN) channels, known to mediate $I_{\mathrm{H}}$ in other species (Santoro et al., 1998, 2000). In particular, the intermediate time constant of activation (on the order of hundreds of milliseconds) of the male Xenopus $I_{\mathrm{H}}$ resembles the currents mediated by HCN2 channels in mammals (Moroni et
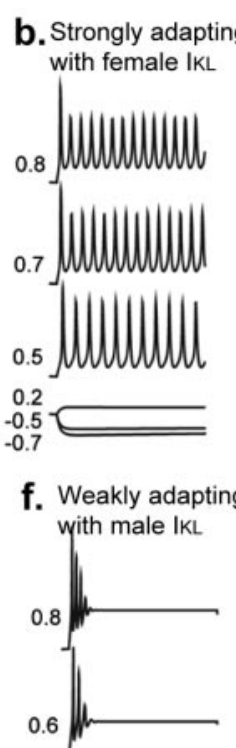

0.6
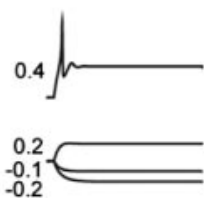

f. Weakly adapting
C. Strongly adapting with female IKL, no IH

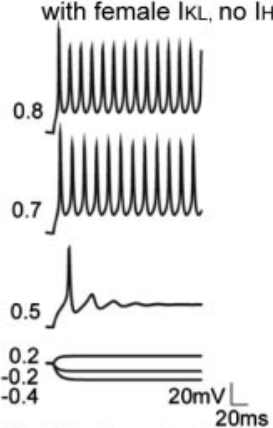

g. Weakly adapting with male IKL and IH

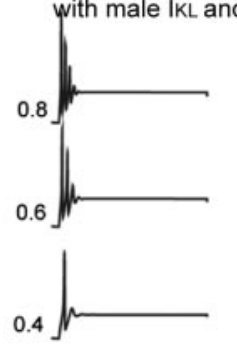

0.2
-0.1

$-0.1$ d. Male action potential and IKL current

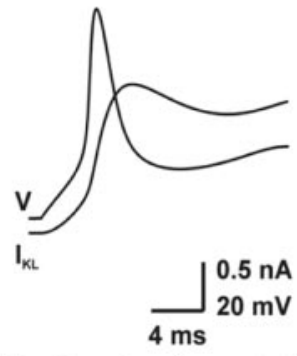

h. Female action potential and IKL current

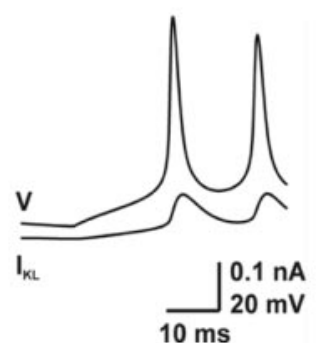

$20 \mathrm{mV} L$

Figure 6. Current-clamp simulation of strongly adapting male and weakly adapting female model cells. $a, e$, The firing patterns of model male $(a)$ and model female $(e)$ neurons in response to depolarizing current steps. $d, h$, The activation of the lowtheshold $\mathrm{K}^{+}$currents $\left(I_{\mathrm{KL}}\right)$ during suprathreshold depolarizations in typical male and female neurons, respectively. $b$, The firing parte me nuron when the voltage of half-maximal activation of the low-threshold $\mathrm{K}{ }^{+}$currents was changed to

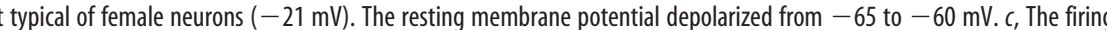
政 female cell now adapted rapidly. $g$, The firing patterns of a model female neuron with addition of the male $I_{H}$ to $f$. The resting membrane potential was restored to $-65 \mathrm{mV}$. Amplitudes of applied currents (nanoamperes) are shown to the left of the traces.

Table 3. Maximum spike latency of model neurons shown in Figure 6

\begin{tabular}{ll}
\hline Model neuron type & Maximum spike latency (msec) \\
\hline Strongly adapting male model & 10.7 \\
$\begin{array}{l}\text { Strongly adapting male model with female } I_{\mathrm{KL}} \\
\text { Strongly adapting male model with female } I_{\mathrm{KL},}\end{array}$ & 17.1 \\
$\begin{array}{l}\text { Weakly adapting female model } \\
\text { Weakly adapting female model with strongly }\end{array}$ & 25 \\
$\quad \begin{array}{l}\text { adapting male } I_{\mathrm{KL}} \\
\text { Weakly adapting female model with strongly } \\
\quad \text { adapting male } I_{\mathrm{KL}} \text {, with } I_{\mathrm{H}}\end{array}$ & 13.9 \\
\hline
\end{tabular}

al., 2000; Santoro et al., 2000; Altomare et al., 2001). The channels responsible for the low-threshold potassium currents are likely to be delayed rectifier $\mathrm{K}^{+}$channels that activate at negative potentials with little inactivation. $\mathrm{Ca}^{2+}$-activated $\mathrm{K}^{+}$channels are unlikely candidates because the neurons were dialyzed with EGTA in our experiments such that a significant contribution of these currents at negative potentials is unlikely. The low-threshold potassium currents could be attributable to a channel subunit specific to males or to a shared channel type, the voltage of activation of which is shifted by sex-specific modulatory mechanisms such as phosphorylation. For example, constitutive activation of the Kv3.1 potassium channel by the enzyme casein kinase II can shift 
the voltage dependence of activation to more positive potentials by $>20 \mathrm{mV}$ (Macica and Kaczmarek, 2001).

Quantitative sex differences in voltage-activated currents have been observed in various neurons and in muscle cells involved in reproductive behaviors of vertebrates [motoneurons in spinal nucleus of the bulbocavernosus (Manabe et al., 1991); neurons in the vomeronasal organ (Fadool et al., 2001); and electrocytes of Sternopygys electric fish (Ferrari et al., 1995)]. These differences probably reflect quantitative differences in ion channel density or modulation of ion channel conductance/kinetics via phosphorylation or other modulatory mechanisms (Fadool et al., 1991; Manabe et al., 1991). In contrast, the near-qualitative sex differences in the expression of $I_{\mathrm{H}}$ in male and female Xenopus vocal motoneurons suggest that the channel underlying these currents is essentially male specific. Sex-specific expression of ion channels has not been reported, to date, but may be a strategy that the CNS uses to differentiate functionally the behavioral patterns of males and females.

How do strongly and weakly adapting motoneurons contribute to male and female vocal behaviors? Because the spike patterns in response to step depolarizations do not match those previously recorded spike patterns in vivo (Yamaguchi and Kelley, 2000), synaptic inputs must be patterned. Descending synaptic inputs to laryngeal motoneurons are likely to match the temporal pattern of vocal output. These synaptic inputs, in turn, are likely to be processed differently by strongly and weakly adapting laryngeal motoneurons. Strong spike frequency adaptation, together with the short spike-onset latency of strongly adapting neurons, probably contributes to high temporal fidelity in the translation of synaptic inputs into spike trains. These characteristics are commonly found in neural pathways in which accurate temporal coding is important [e.g., the auditory system (for review, see Carr et al., 2001)] and probably help strongly adapting motoneurons to follow patterned input reliably with high precision to produce the very rapid spike trains that generate fast trains of clicks. The less precise time coding of weakly adapting neurons would suffice for production of slow clicks with more variable interclick intervals.

The temporal locking of spikes to descending inputs in strongly adapting motoneurons may also help enhance the firing synchrony of populations of neurons. Rapid clicks of male Xenopus are produced by highly synchronous firing of laryngeal motoneurons, whereas slow clicks of males and females are produced by less synchronous firing of motoneurons in vivo (Yamaguchi and Kelley, 2000). In response to common synaptic inputs, a population of strongly adapting neurons with precisely timed spikes is likely to fire more synchronously than a population of weakly adapting neurons with variable spike delays. Given the suitability of strongly adapting neurons for accurate temporal coding, one hypothesis is that the rapid clicks of males are produced by a population of strongly adapting motoneurons. In contrast, slower clicks of males and females may be generated by a mixed population of strongly and weakly adapting motoneurons. The sex-specific proportion of strongly and weakly adapting motoneurons could reflect the sex-specific demands of male and female vocal behaviors.

The spike timing of strongly and weakly adapting neurons shows some resemblance to dynamical models for neuron termed type II and type I dynamics, which have been proposed to have different roles in rate coding (Rinzel and Ermentrout, 1989; Gutkin and Ermentrout, 1998). In type I neurons, as in the weakly adapting motoneurons, the firing frequency is continuously dependent on the input current. For type II neurons, as in strongly adapting neurons, spike latency is not so sensitive to the amplitude of the stimulus. Type II model neurons, however, generate intrinsic oscillations in response to a wide range of stimulus inputs. In contrast, strongly adapting neurons do not fire repetitively in response to suprathreshold depolarization.

We have identified functional specializations of vocal motor pathways at the level of the laryngeal motoneuron. Many sexually differentiated features of the vocal system depend on exposure to circulating gonadal steroids either during development or in adulthood (Kelley, 1996). Sex-specific vocalizations of Xenopus are governed by the circulating levels of testosterone in adulthood; vocalizations of adult females can be masculinized by administering testosterone for 13 weeks (Hannigan and Kelley, 1986), suggesting that the central vocal pathways of females can be functionally masculinized by testosterone to produce maletypical rhythms. How the sex-specific cellular properties that we describe here are modified by hormones, and how steroids gain access to expression of specific ionic conductances, remains to be determined.

\section{References}

Altomare C, Bucchi A, Camatini E, Baruscotti M, Viscomi C, Moroni A, DiFrancesco D (2001) Integrated allosteric model of voltage gating in HCN channels. J Gen Physiol 17:519-532.

Carr CE, Soares D, Parameshwaran S, Perney T (2001) Evolution and development of time coding systems. Curr Opin Neurobiol 11:727-733.

DiFrancesco D, Tortora P (1991) Direct activation of cardiac pacemaker channels by intracellular cyclic AMP. Nature 351:145-147.

Fadool DA, Wachowiak M, Brann JH (2001) Patch-clamp analysis of voltage-activated and chemically activated currents in the vomeronasal organ of Sternotherus odoratus (Stinkpot/musk turtle). J Exp Biol 204:4199-4212.

Ferrari MB, McAnelly ML, Zakon HH (1995) Individual variation in and androgen modulation of the sodium current in electric organ. J Neurosci 15:4023-4032.

Goldman MS, Golowasch J, Marder E, Abbott LF (2001) Global structure, robustness, and modulation of neuronal models. J Neurosci 21:5229-5238.

Gutkin BS, Ermentrout GB (1998) Dynamics of membrane excitability determine interspike interval variability: a link between spike generation mechanisms and cortical spike train statistics. Neural Comput 10:1047-1067.

Hahnloser RH, Kozhevnikov AA, Fee MS (2002) An ultra-sparse code underlies the generation of neural sequences in a songbird. Nature 419:65-70.

Hannigan P, Kelley D (1986) Androgen-induced alterations in vocalizations of female Xenopus laevis: modifiability and constraints. J Comp Physiol A 158:517-528.

Harris NC, Libri V, Constanti A (1994) Selective blockade of the hyperpolarization-activated cationic current $(I h)$ in guinea pig substantia nigra pars compacta neurones by a novel bradycardic agent, Zeneca ZM 227189. Neurosci Lett 176:221-225.

Kelley DB (1996) Sexual differentiation in Xenopus laevis. In: The biology of Xenopus (Tinsley R, Kobel H, eds), pp 143-176. Oxford: Oxford UP.

Kelley DB (2002) Hormonal regulation of motor output in amphibians: Xenopus laevis vocalizations as a model system. In: Hormones, brain and behavior, Vol 2 (Pfaff D, Arnold A, Etgen A, Fahrbach S, Rubin R, eds), pp 445-468. San Diego: Academic.

Kiehn O, Kjaerulff O, Tresch MC, Harris-Warrick RM (2000) Contribution of intrinsic motor neuron properties to the production of rhythmic motor output in the mammalian spinal cord. Brain Res Bull 53:649-659.

Lindau M, Neher E (1988) Patch-clamp techniques for time-resolved capacitance measurements in single cells. Pflugers Arch 411:137-146.

Liu SJ, Kaczmarek LK (1998) Depolarization increases the expression of the Kv3.1 potassium channel in developing inferior colliculus neurons. J Neurosci 18:8758-8769.

Lüthi A, McCormick DA (1998) H-current: properties of a neuronal and network pacemaker. Neuron 21:9-12.

Lutwig A, Zong X, Jeglitsch M, Hofmann F, Biel M (1998) A family of 
hyperpolarization-activated mammalian cation channels. Nature 393:587-591.

Lutwig A, Zong X, Stieber J, Hullin R, Hofmann F, Biel M (1999) Two pacemaker channels from human heart with profoundly different activation kinetics. EMBO J 18:2323-2393.

Macica CM, Kaczmarek LK (2001) Casein kinase 2 determines the voltage dependence of the Kv3.1 channel in auditory neurons and transfected cells. J Neurosci 21:1160-1168.

MacLean JN, Zhang Y, Johnson BR, Harris-Warrick RM (2003) Activityindependent homeostasis in rhythmically active neurons. Neuron $37: 109-120$.

Magee JC (1999) Dendritic hyperpolarization-activated currents modify the integrative properties of hippocampal CA1 pyramidal neurons. J Neurosci 18:7613-7624.

Manabe T, Araki T, Takahashi T, Kuno M (1991) Membrane currents recorded from sexually dimorphic motoneurons of the bulbocavernosus muscle in neonatal rats. J Physiol (Lond) 440:419-435.

Marder E, Bucher D (2001) Central pattern generators and the control of rhythmic movements. Curr Biol 11:986-996.

Moroni A, Barbuti A, Altomare C, Viscomi C, Morgan J, Baruscotti M, DiFrancesco D (2000) Kinetic and ionic properties of the human HCN2 pacemaker channel. Eur J Physiol 439:618-626.

Pape HC (1996) Queer current and pacemaker: the hyperpolarizationactivated cation current in neurons. Annu Rev Physiol 58:299-327.

Perney TM, Kaczmarek LK (1997) Localization of a high threshold potassium channel in the rat cochlear nucleus. J Comp Neurol 386:178-292.

Richardson FC, Kaczmarek LK (2000) Modification of delayed rectifier potassium currents by the Kv9.1 potassium channel subunit. Hear Res 147:21-30.

Rinzel J, Ermentrout GB (1989) Analysis of neural excitability and oscillations. In: Methods in neuronal modeling (Koch K, Segev I, eds). Cambridge, MA: Massachusetts Institute of Technology.

Santoro B, Chen S, Lüthi A, Pavlids P, Shumyatsky GP, Tibbs GR, Siegelbaum SA (1998) Molecular and functional heterogeneity of hyperpolarization activated pacemaker channels in the mouse CNS. J Neurosci 20:5264-5275.
Santoro B, Liu DT, Yao H, Bartsch D, Kandel ER, Siegelbaum SA, Tibbs GR (2000) Identification of a gene encoding a hyperpolarization-activated pacemaker channel of brain. Cell 93:717-729.

Schmidt RS (1976) Neural correlates of frog calling: isolated brain stem. J Comp Physiol A 108:99-113.

Simpson HB, Tobias ML, Kelley DB (1986) Origin and identification of fibers in the cranial nerve IX-X complex of Xenopus laevis: Lucifer Yellow backfill in vitro. J Comp Neurol 244:430-444.

Suthers RA, Goller F, Pytte C (1999) The neuromuscular control of birdsong. Philos Trans R Soc Lond B Biol Sci 354:927-939.

Tobias ML, Kelley DB (1987) Vocalizations by a sexually dimorphic isolated larynx: peripheral constraints on behavioral expression. J Neurosci 7:3191-3197.

Tobias ML, Viswanathan SS, Kelley DB (1998) Rapping, a female receptive call, initiates male-female duets in the South African clawed frogs. Proc Natl Acad Sci USA 95:1870-1875.

Tobias ML, O'Hagan R, Horng SH, Kelley DB (2003) Vocal communication between male Xenopus laevis; behavioral context and sexual state. Anim Behav, in press.

Vu ET, Schmidt MF, Mazurek ME (1998) Interhemispheric coordination of premotor neural activity during singing in adult zebra finches. J Neurosci 18:9088-9898.

Wang L-Y, Gan L, Forsythe ID, Kaczmarek LK (1998) The Kv3.1 potassium channel is required for high frequency firing in mouse auditory neurons. J Physiol (Lond) 509:183-194.

Wetzel D, Haerter U, Kelley DA (1985) A proposed efferent pathway for mate calling in South African clawed frogs, Xenopus laevis: tracing afferents to laryngeal motor neurons with HRP-WGA. J Comp Physiol A 157:749-761.

Yager DD (1992) A unique sound production mechanism in the pipid anuran Xenopus borealis. Zool J Linn Soc 104:351-375.

Yamaguchi A, Kelley DB (2000) Generating sexually differentiated vocal patterns: laryngeal nerve and EMG recordings from vocalizing male and female African clawed frogs (Xenopus laevis). J Neurosci 20:1559-1567.

Yu AC, Margoliash D (1996) Temporal hierarchical control of singing in birds. Science 273:1871-1875. 